\title{
A satellite-based snow cover climatology (1985-2011) for the European Alps derived from AVHRR data
}

\author{
F. Hüsler ${ }^{1}$, T. Jonas ${ }^{2}$, M. Riffler ${ }^{1}$, J. P. Musial ${ }^{1}$, and S. Wunderle ${ }^{1}$ \\ ${ }^{1}$ Institute of Geography and Oeschger Center for Climate Change Research, University of Bern, Bern, Switzerland \\ ${ }^{2}$ WSL Institute for Snow and Avalanche Research SLF, Davos Dorf, Switzerland
}

Correspondence to: F. Hüsler (fabia.huesler@giub.unibe.ch)

Received: 31 May 2013 - Published in The Cryosphere Discuss.: 24 June 2013

Revised: 10 November 2013 - Accepted: 26 November 2013 - Published: 10 January 2014

\begin{abstract}
Seasonal snow cover is of great environmental and socio-economic importance for the European Alps. Therefore a high priority has been assigned to quantifying its temporal and spatial variability. Complementary to land-based monitoring networks, optical satellite observations can be used to derive spatially comprehensive information on snow cover extent. For understanding long-term changes in alpine snow cover extent, the data acquired by the Advanced Very High Resolution Radiometer (AVHRR) sensors mounted onboard the National Oceanic and Atmospheric Association (NOAA) and Meteorological Operational satellite (MetOp) platforms offer a unique source of information.

In this paper, we present the first space-borne $1 \mathrm{~km}$ snow extent climatology for the Alpine region derived from AVHRR data over the period 1985-2011. The objective of this study is twofold: first, to generate a new set of cloudfree satellite snow products using a specific cloud gap-filling technique and second, to examine the spatiotemporal distribution of snow cover in the European Alps over the last $27 \mathrm{yr}$ from the satellite perspective. For this purpose, snow parameters such as snow onset day, snow cover duration (SCD), melt-out date and the snow cover area percentage (SCA) were employed to analyze spatiotemporal variability of snow cover over the course of three decades. On the regional scale, significant trends were found toward a shorter SCD at lower elevations in the south-east and south-west. However, our results do not show any significant trends in the monthly mean SCA over the last $27 \mathrm{yr}$. This is in agreement with other research findings and may indicate a deceleration of the decreasing snow trend in the Alpine region. Furthermore, such data may provide spatially and temporally homogeneous snow information for comprehensive use in related
\end{abstract}

research fields (i.e., hydrologic and economic applications) or can serve as a reference for climate models.

\section{Introduction}

Alpine snow cover not only represents a significant geophysical variable in the climate system (IPCC, 2007) but also plays a major role in regulating mountain ecosystems (Jones, 2001; Jonas et al., 2008) and influences hydrological regimes (EEA, 2009). Furthermore, the alpine snow pack is considered an important economic factor, which has a large impacts on tourism (Elsasser and Bürki, 2002; Agrawala, 2007) and hydropower production (Hänggi and Weingartner, 2012). Likewise, snow is a critical variable in flood forecasting (Jasper et al., 2002) and reservoir management but also for avalanche warning and public safety services (Fuchs and Brandl, 2005). Therefore, it is of paramount interest to determine and quantify its variability on various spatial and temporal scales. In this context, "snow cover" has been officially declared an Essential Climate Variable (ECV) by the Global Climate Observing System (GCOS) and high priority is assigned to enhancing and maintaining snow cover observations (WMO, 2010, 2011).

Snow parameters and their spatiotemporal distribution are commonly monitored using three methodologies (or combinations of them), each one having its strengths and limitations. Ground-based monitoring networks provide valuable long time series data to investigate temporal variability and long-term trends (Beniston, 1997; Scherrer et al., 2004; Scherrer and Appenzeller, 2006; Laternser and Schneebeli, 2003; Marty, 2008; 
Hantel and Hirtl-Wielke, 2007; Marty and Meister, 2012). However spatial analyses are constrained to dense station networks. Modeling approaches provide another possibility to increase our knowledge of the cryospheric processes. For snow cover, models range from considering simple relations between precipitation and air temperature (Rango and Martinec, 1995) through to complex physical interactions at different spatial scales (Marks et al., 1999; Lehning et al., 2006). However, while conceptual models require regional calibration, complex process-oriented models are often challenged by the enormous requirements as to input data (Magnusson et al., 2011). In addition, they may still rely on a set of assumptions and auxiliary data, which by themselves include uncertainties. Complementary rather than substitutionally, satellite remote sensing (RS) has become an attractive option to study snow cover variability on a wide range of spatial and temporal scales (König et al., 2001; Dietz et al., 2012; Metsämäki et al., 2012). The major advantage of visible RS is its ability to provide area-wide and spatially comprehensive surface information with a regular repeatability of measurements, even in remote areas. However, limitations include cloud cover impeding surface view, the obstruction of snow by dense vegetation as well as the surface heterogeneity in mountain areas, which complicates the interpretation of RS data. Nevertheless, climatological snow cover studies based on RS data have been successfully compiled on regional to hemispherical scales (Robinson and Frei, 2000; Armstrong and Brodzik, 2001; Zhao and Fernandes, 2009; Foppa and Seiz, 2012).

Starting in 1960, RS technology has undergone rapid changes. With advanced sensor technologies, new dimensions of monitoring snow properties have been achieved and the measurement accuracy has increased (Rees, 2005; Nolin, 2011; Dietz et al., 2012). Indeed, the exceptional value of older sensors lies in their unique long-term data set. Among these, the AVHRR instrument provides the longest record of visible satellite imagery on a daily basis. The University of Bern has archived daily full-resolution AVHRR data over Europe for almost $30 \mathrm{yr}$ (1984-2012). Using AVHRR for longterm climate studies, however, means having to properly deal with the many limitations of this sensor, such as calibration uncertainties and changing channel configuration, which have been addressed in various studies (James and Kalluri, 1994; Cihlar et al., 2004; Heidinger et al., 2010; Gutman and Masek, 2012). The main difficulty therefore lies in the appropriate raw data processing, which is a key requirement to access the full potential of the archived data.

This study presents and analyzes the first consistent space-borne $1 \mathrm{~km}$ snow coverage climatology derived from AVHRR instruments over the European Alps for the period 1985-2011. A robust and validated snow retrieval algorithm (Hüsler et al., 2012) was applied to derive real surface variability with consistent results. Hence, the objectives of this study are (1) to compile a set of cloud-free satellite snow composites using a spatial and temporal gap-filling method and (2) to employ these composites to analyze the spatiotemporal snow cover variability in the Alpine region over the last three decades. This is done using snow parameters such as snow onset day, snow cover duration, snow melt-out date, and the snow cover area percentage (SCA).

Given the need for spatial representations of the alpine snow cover and its variations for many research fields, including hydrological and ecological applications, socioeconomic questions or albedo parameterization in climate models, this data set is considered a powerful contribution to a regional climate observing system.

\section{Study area}

The topography and delineation of the Alpine region as defined by the Alpine Convention (http://www.alpconv.org/ index_en, accessed December 2012) are shown in Fig. 1. The complex topography of the European Alps, coupled with the varying altitudinal and climatic conditions, essentially influences the spatial and temporal occurrence and duration of the snow cover. Consequently, it allows us to investigate highly variable climatic conditions on comparatively short horizontal and vertical distances. For our investigations, the study area was additionally subdivided into four distinct climatic regions which are assumed to reflect different snow cover regimes. These subregions are defined according to the statistical regionalization of different climate elements such as precipitation and temperature (Auer et al., 2007). The most distinct climate border is found along the central Alpine crest. It represents the continental transition zone from the temperate westerly to the Mediterranean subtropical climate. A second continental scale climate border is identified between the (western) oceanic influenced and the (eastern) continental part of Eurasia. This rather uniform border roughly follows the 12th degree eastern longitude and was not found to be caused by any topographic feature (Auer et al., 2007). The size, altitudinal distribution and climatic classification of the study area and each subregion are listed in Table 1.

\section{Data}

\subsection{AVHRR data set}

The data set consists of daily $1 \mathrm{~km}$ gridded binary snow cover maps generated from a full-resolution AVHRR data archive, which is unique in its form as it represents the longest and most comprehensive full-resolution RS data set for the European Alps (Hüsler et al., 2011). In this study, the data is restricted to the five-channel instruments AVHRR/2 and AVHRR $/ 3$ to ease the discrimination of thin cirrus clouds. The snow detection relies on a threshold approach that capitalizes on the spectral properties of snow in the visible and the near infrared spectrum and it is applicable to any kind of AVHRR sensor generation with consistent results. Originally 
Table 1. Distinct properties of the Alps and its subregions in terms of altitude distribution, extent and climatic influence. Color encoding corresponds to Fig. 1.

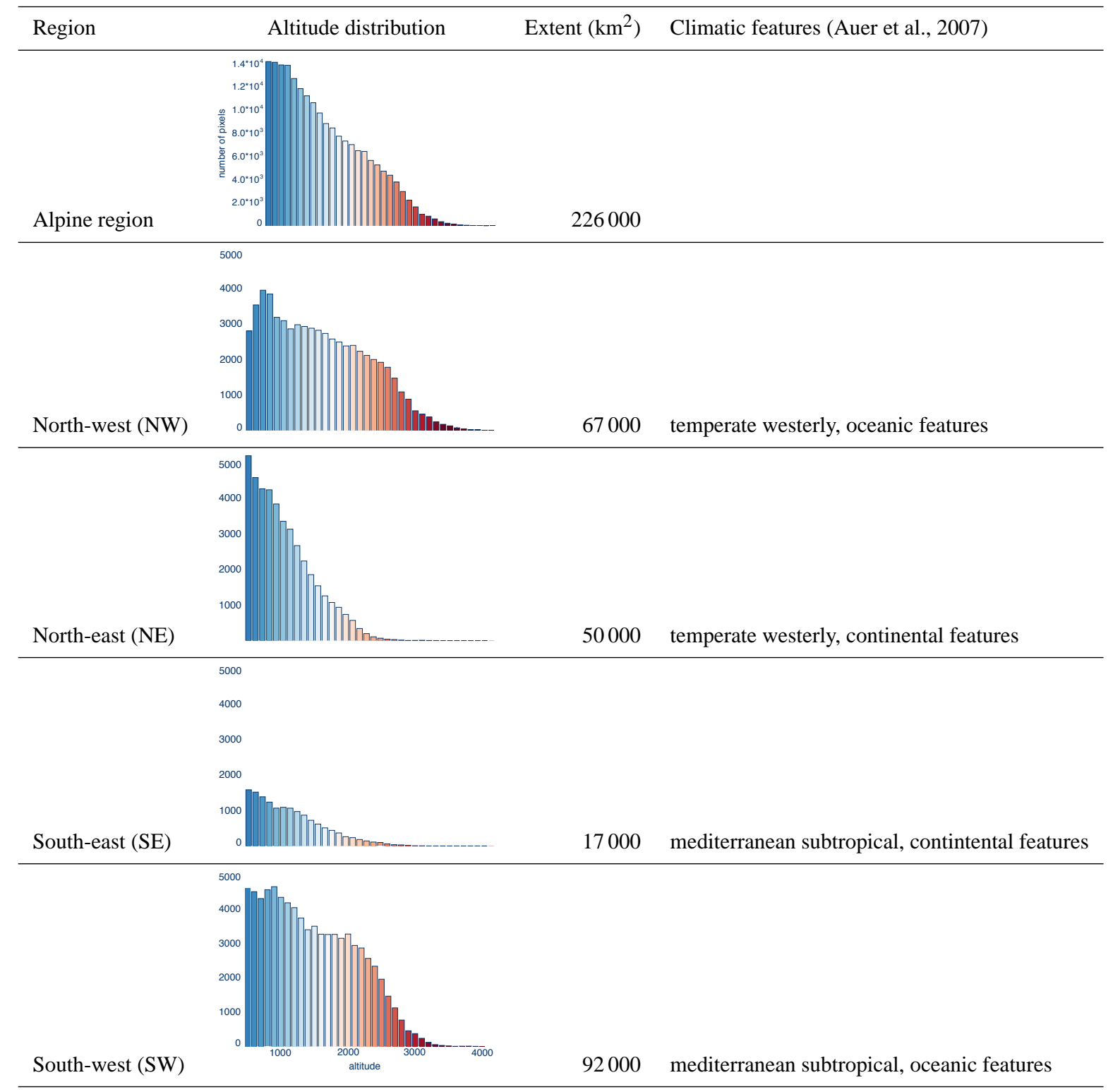

developed for rather flat areas in Canada (Khlopenkov and Trishchenko, 2007), the algorithm was adapted and optimized for use in complex terrain. The modifications of the original algorithm basically include changes in the thresholds, taking into account land cover types and topographic features such as terrain shadow. In addition, a distinct snow probability map comes with each snow map, providing a pixel-wise probability index of snow occurrence based on logistic regression (Hosmer and Lemeshow, 2000). A detailed description of the algorithm itself and an extensive validation of the product can be found in Hüsler et al. (2012). The overall classification accuracy of snow detection was found to be good, with an average probability of detection of up to
$90 \%$ depending on land cover class, acquisition geometry, and aspect.

The number of available scenes per season is displayed in Fig. 2. Included platforms are NOAA-09, 11, and 14 equipped with AVHRR/2 and NOAA-16, 17, 18, 19, and MetOp-A carrying an AVHRR/3 instrument onboard. To constrain the influence of the snow's distinct bidirectional distribution function effects (Wiscombe and Warren, 1980) and strong shadowing due to low sun angles, we only use midday and early-afternoon overpasses. This, however, comes at the cost of two small data gaps in 1994 as well as in 2000, when only early-morning platforms were in orbit. Additionally, the maximum sensor zenith angle was constrained 


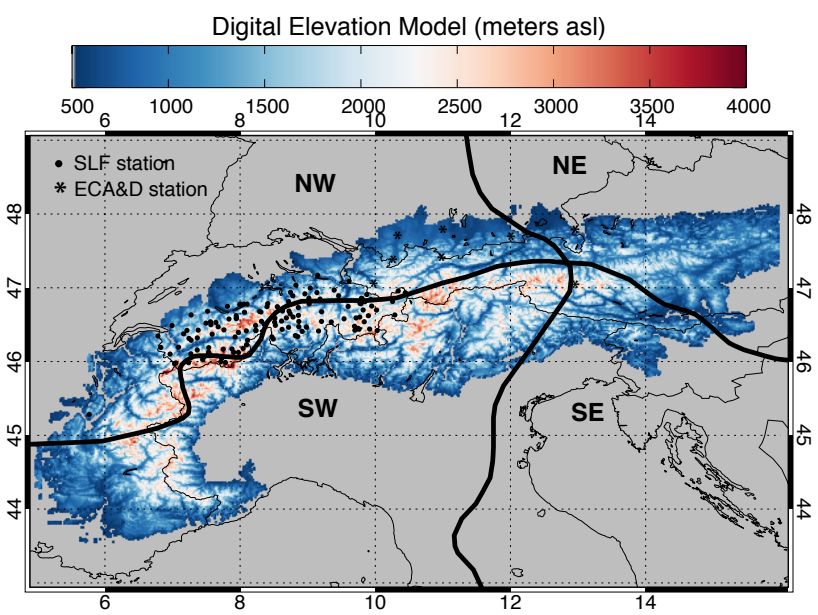

Fig. 1. Digital elevation model of the Alpine region. Black dots represent station locations used for the validation of the product. Bold lines indicate the subdivision into the four subregions (northwest, north-east, south-east and south-west) according to Auer et al. (2007). Data for the extra-alpine areas were not displayed.

to $35^{\circ}$ since the snow mask accuracy was found to decrease with the distance to nadir.

An irregular distribution over such a long period is inevitable, mainly due to a varying number of platforms simultaneously in orbit. This needs to be taken into account in time series applications. Generally, there is an increasing trend in the data availability. While the number of scenes from 1985 to 1989 can primarily be used for temporal applications relying on monthly mean data, the record provides an almost complete daily coverage from 1989-2002 and reaches a maximum of 2-3 overpasses per day from 2003 to 2011. Therefore, depending on the type of application, two different time periods are considered in the study at hand. First, 1985 to 2011 for the monthly mean snow cover time series and second, 1991-2011 for spatial applications relying on daily data coverage.

\subsection{Gridded station data set and snow depth measurements}

As a reference data set, a gridded snow depth climatology based on in situ measurements (cf. Rhyner et al., 2002; Jonas et al., 2009) available for Switzerland was employed. This data set consists of daily snow depth measurements from 133 stations for the period of 1989-2009 and is therefore considered stable over time (see also Hüsler et al., 2012). To avoid the problem of comparing point scale data (stations) to area scale data (satellite), the snow depth data were mapped to the AVHRR grid using a snow data assimilation scheme based on Auer et al. (2004) and available from December to April.

In addition, in situ snow depth information from 48 automatic stations over the time period 2003-2010 were used to validate the gap-filling procedure to include longer time pe- riods, to assess the seasonal performance, and to ensure that the gap-filling does not significantly lower the initial accuracy. The stations are distributed all over Switzerland covering different elevation ranges and the data are provided by the WSL Institute for Snow and Avalanche Research SLF. Snowdepth data is recorded automatically and available daily. To expand the validation beyond Switzerland, the 8 European Climate Assessment \& Data stations (Haylock et al., 2008) lying within the Alpine Region were additionally included in the reference data set. The locations of all stations are illustrated in Fig. 1 and they are mainly positioned at elevations between 480 and $3100 \mathrm{~m}$ a.s.l.

\section{Methods}

\subsection{Snow mask gap-filling procedure}

One major drawback of optical sensors such as AVHRR is their inability to provide surface information under cloudy conditions. This strongly limits the number of useful snow observations as abundant cloud cover is present in the Alpine region, particularly during the winter season.

Various techniques have been developed to reduce cloudcovered pixels from optical imagery. They mostly include spatial and temporal filtering techniques (i.e., Voigt, 2000; Gafurov and Bárdossy, 2009; Parajka et al., 2010), multiday maximum snow cover composites, or a combination of acquisitions from similar sensors (i.e., Parajka and Blöschl, 2008; Wang et al., 2008; Hall et al., 2010).

In this study, we use a combination of spatial and temporal gap-filling techniques to mitigate the influence of clouds. In the first step we applied straightforward spatial filtering using the regional snow line estimation (SNOWL) method as suggested by Parajka et al. (2010). This procedure reclassifies cloudy pixels to snow or snow-free land, according to their position, relative to the current snow line elevation. In their publication, the accuracy of this method was assessed using 754 climate stations and it was found that the SNOWL method provides robust snow cover mapping over Austria, even under abundant cloud cover of $90 \%$ (Parajka et al., 2010). To avoid blurring regional differences by assuming one snow line elevation for the whole Alpine region, the reclassification was done separately for each of the four distinct climatic regions (cf. Sect. 2). In the second step, a forward (pixel value of closest clear-sky observation in the forward time direction) and a backward (pixel value of closest clearsky observation in the backward time direction) gap-filling procedure (Foppa and Seiz, 2012) was carried out over a period of 10 days in both directions. Generally, the time period for filtering needs to be as short as possible but long enough to get cloud-free composites, especially during winter when cloud cover is frequent. Hence, it is a trade-off between remaining clouds and the blurring of snow information. Analyses of the amount of cloud and no data value 


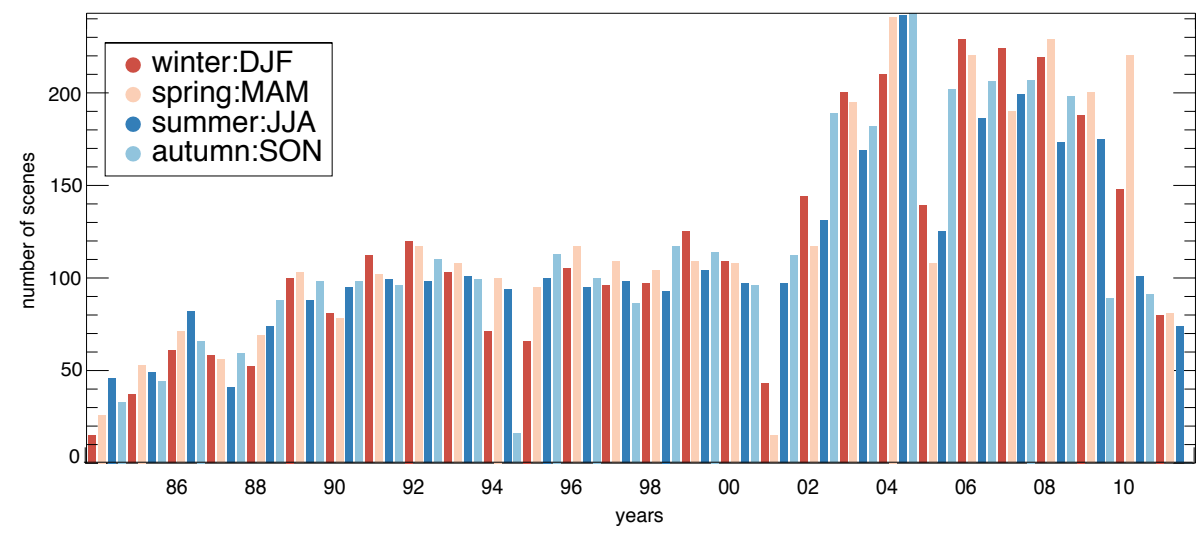

Fig. 2. Archived AVHRR overpasses illustrated by season and number of scenes for the period 1984-2011.

reduction showed that a minimum of 10 days is required to render cloud-free images. Even though this period might be slightly shorter for later years with abundant data, the number of days for the filtering is determined by the results for earlier years with limited data availability. Furthermore, it needs to be kept in mind that the closest clear-sky observation is used for the composite, which means that 10 days is the maximum amount of days to search for clear-sky observations and only applies to a small amount of pixels.

For the final product, the mean SCA value between the two values (the one from the forward and the one from the backward filtered product for a specific day) was taken. This is based on the assumption that the under- or overestimation in one time direction is minimized by averaging the results from the forward and the backward gap-filling procedures (Foppa and Seiz, 2012).

\subsection{Snow gap-filling accuracy assessment}

To assess the accuracy and consistency of the gap-filled product, two types of reference data sets were used: gridded snow depth data and point snow depth data. For the comparison of the gridded data set to the satellite gap-filled product, the SCA over Switzerland was calculated for both products for each day as described in Sect. 4.3. Different thresholds are suggested in literature to infer snow coverage from measured snow depth, which is assumed to approximately represent a $50 \%$ fractional snow cover in complex alpine terrain at $1 \mathrm{~km}$ resolution. These commonly range from $1 \mathrm{~cm}$ (Parajka and Bloeschl, 2006; Foppa and Seiz, 2012) over $4 \mathrm{~cm}$ (Wang et al., 2009) to $5 \mathrm{~cm}$ (Romanov et al., 2002). Here, a threshold of $5 \mathrm{~cm}$ was used to calculate snow cover percentage to avoid shallow snow depth or patchy snow cover not detectable by satellite. Slopes steeper than $20^{\circ}$ were excluded from the analyses as they are not considered being well represented in the two data sets.
For the point-wise validation the automated snow stations were considered as ground truth and were compared to the pixel closest to each station. The snow depth is measured from above with an ultrasonic snow depth sensor (Lehning et al., 1999). During the snow-free season, the same sensor measures vegetation height. Hence, a pre-processing of the station data was necessary. For this purpose, a robust automated correction algorithm was implemented to find the first and the last occurrence of a location specific minimum value to determine the snow melt out and onset timing. Values in between were set to zero as these are assumed to correspond to vegetation height rather than to snow depth. Quality checking indicated a good performance of the correction although short-term snow events after complete melt out and before permanent snow onset might not be represented in the reference data. Methodologically, the comparison was carried out by means of investigating the accuracy index (ACC), defined as the sum of correctly classified pixels divided by the total number of compared (i.e., cloud-free) pixels. As above, the station was classified to be snow covered when the measured snow depth was equal or higher to $5 \mathrm{~cm}$. Furthermore, the misclassified pixels were evaluated in terms of snow over(SO) and underestimation (SU), both relating the sum of incorrectly classified pixels to the total number of compared (i.e., cloud-free) pixels as suggested by Parajka et al. (2010). For this type of validation it must be kept in mind, that, in mountainous regions, steep elevation gradients are common and one single AVHRR pixel may include both valleys and mountain peaks with elevation differences up to $1200 \mathrm{~m}$ at alpine sites. As a consequence, differences may be observed when a grid cell value is compared to a in situ point observation in complex terrain.

\subsection{Snow cover parameters}

To estimate the temporal distribution, the snow cover area percentage (SCA) is a frequently used measure (Armstrong and Brodzik, 2001; Gao et al., 2012). It is defined as the 
percentage area of a certain reference area (i.e., the Alpine region) covered by snow. More specifically, it represents the ratio of snow covered pixels in the reference area to all pixels in the reference area at a specific point in time. For time series analysis, standardized anomalies with respect to month are computed using:

$A=(X-\mu) / \sigma$,

where $X$ is the single monthly mean value, calculated as the mean of all daily values available for a specific month. The $\mu$ value is the long-term mean and $\sigma$ the standard deviation of the respective month.

The snow cover duration (SCD) is another parameter of broad interest, that is, for winter tourism, water resource management, agricultural and disaster/flood forecasting. To make our results comparable in a broader context, we adapted the measures suggested by Wang and Xie (2009) and Gao et al. (2012). Using the gap-filled data product, we calculated the annual SCD using all available scenes within a hydrological year starting from 1 October to 30 September as follows:

$\mathrm{SCD}=\sum_{i=0}^{N} D_{i}$,

where $N$ is the total number of scenes within the hydrological year; $D_{i}$ is the actual pixel value for a one day composite within the period ( 0 for snow free, 1 for snow). This parameter basically counts pixel-wise the number of snow values and represents the total number of snow days for one hydrological year. The SCD anomalies provide a measure for the difference between the SCD value of a specific year compared to the long-term mean SCD. Likewise, monthly anomalies represent the difference between the actual monthly value and the long-term mean value for the respective month.

In the context of an anticipated climate change, the snow cover onset, as well as melt-out timing, represent valuable indicators. Following the explanations of Wang and Xie (2009), these measures are captured in the Snow Cover Onset Day (SCOD), which represents the first day of snow occurrence for a certain pixel,

$\mathrm{SCOD}=D-\mathrm{SCD}^{\prime}$

where $\mathrm{SCD}^{\prime}$ is the snow cover duration within the period from 1 October (DOY $=274$ or 275) to 31 December (DOY $=365$ or 366 ) and $D$ is the Day Of Year (DOY) of 31 December (DOY $=365$ or 366 ), when the area is supposed to be covered by snow. The Snow Cover Melting Day (SCMD), that is, the last day with snow occurrence within a pixel, is defined as

$\mathrm{SCMD}=D+\mathrm{SCD}^{\prime \prime}$, where $\mathrm{SCD}^{\prime \prime}$ is the snow cover duration within the period from 1 January $(\mathrm{DOY}=1)$ to 31 May $(\mathrm{DOY}=151$ or 152$)$ and $D$ is January $1(\mathrm{DOY}=1)$ of the respective year.

Since these measures rely on the continuous availability of data, errors might arise from single missing scenes. Therefore, only the period of 1991-2011 (excluding the years 1995 and 2001) was considered when the amount of adjacent missing values is reasonably small $(<10)$. The SCOD and SCMD parameters are most meaningful in areas with stable snow cover (i.e., with a continuous snow cover between the onset and the melt out). For regions with intermittent snow cover, SCOD and SCMD count the snow days within the indicated period but are not affected by repeated short-term snow events that often occur at lower elevations. A slightly modified approach was tested, setting the SCOD (SCMD) date when a pixel was snow-covered for a certain number of consecutive days. This, however, resulted in single missing or gap-filled scenes which completely distorted the parameters. Therefore, the measures described here were concluded to be useful bearing in mind that the results are of most interest in those regions with continuous seasonal snow cover.

\section{Results}

\subsection{Gap-filled product}

The results of the spatial and temporal filtering process for all available scenes for the period January to April 2006 are illustrated in Fig. 3. This analysis was restricted to Switzerland due to the limited extent of the station reference data set (see Sect. 3.2). The values of the relative area percentage of the classes snow, snow free, cloud and invalid pixels per scene change considerably from the unfiltered scenes (a) to the final filtered scenes (c). As an intermediate step, panel (b) shows the relative redistribution of the classes after the spatial gap-filling but before the temporal gap-filling. Merely minor changes become apparent as this step affects only a small number of the pixels, which are primarily located at high altitudes. Panel (d) shows the difference between the forward and the backward gap-filling direction and the averaged value as compared to the gridded station data set. The average value is calculated as the mean between the SCA value derived from the forward filtering product and the SCA value of the backward filtering product for a specific day. Only minor differences in the range of $0-10 \%$ between the averaged value and the reference data set are found. Therefore the gap-filling procedure is considered appropriate. The quantitative improvement in terms of cloud reduction after each filtering step is listed in Table 2. While the change from the unfiltered data to the spatially filtered data is relatively small (change in median from $37.2 \%$ to $35.7 \%$ ), the temporal filtering step strongly impacts on the number of cloudy pixels. The amount of clouds and nonvalid pixels is, on average, reduced by $35 \%$ (clouds) and 
$3 \%$ (non-valid). The maximum percentage for the remaining clouds after temporal filtering is only $0.9 \%$. Vice versa, the number of clear-sky pixels (snow covered and snow free) is significantly increased. The snow percentage raises from $26.3 \%$ up to $76.7 \%$ and finally corresponds very well to the same measure derived from the gridded station data set with a median of snow percentage of $73 \%$. Likewise, the number of clear-sky snow-free cases shows an increase of $14 \%$.

The results of the station validation to assess the seasonal and filtered accuracy of the snow product are shown in Fig. 4 and consist of three box plots. The topmost plot (a) illustrates the ACC for the four products (unfiltered, spatially filtered, forward and backward filtered) for all months while (b) and (c) show the SU and SO errors, respectively. The mean annual accuracy ranges from $90 \%$ (for unfiltered and spatially filtered) up to $91 \%$ (for the temporally filtered products). As expected, the ACC is high for the full snow season (December-March) and the summer season with values constantly over $90 \%$, whereas it decreases to $82-89 \%$ in the transition season. The mixed pixels including patchy snow cover, different land cover types such as forest, combined with strong elevation differences are suggested to be the reason for this. Also the IQR increases for the transition season, however the general pattern is quite consistent throughout all the years expressed in the comparatively small IQR values.

Except for the month of June and October, the temporally filtered product does not decrease in ACC through the filtering process. On the contrary, it even slightly increases the performance of the snow mapping. This is assumed to be caused by the reduction of misclassified cloudy as snowy pixels (or vice versa). Concerning the errors, they show constantly very low values close to $0 \%$. The reduction of ACC in the transition season is attributed to a slight underestimation of the snow cover in spring (SU error of $6 \%$ (May) and $7.5 \%$ (June) for the unfiltered product). As stated above, this is most probably caused by mixed pixels (i.e., snow lying under trees or snow patches and therefore not being detectable by means of remote sensing). The temporally filtered products show a comparatively higher SU error (up to $12-15 \%$ in June). As daily values are compared, this kind of validation is particularly sensitive to the uncertainty of \pm 10 days inherent in the composite product. During the snow onset season (October, November), however, there is a tendency towards snow overestimation by the temporally filtered products. This is more pronounced for the backward filtered product (SO error of $11 \%$ ) and is probably explained by the filling of pixels with clear-sky information from a couple of days (maximum 10) ahead of the actual day. Especially at lower elevations, the snow-onset process is characterized by several snow-onset events interrupted by melting events. Likewise, it needs to be considered that the correction of the station data described in Sect. 4.2 also leads to some uncertainties in the snow melt-out and onset timing as derived from the station. Particularly short-term spring or summer snowfall events after complete melt-out and minor snowfall events before per- manent snow onset are not represented in the station measurements.

In summary, the influence of the filtering procedure on the accuracy of the product is small. Hence, such spatial and temporal interpolation techniques are considered powerful tools to retrieve more comprehensive surface information. However, they also introduce uncertainties into the data set. Designed to make assumptions about conditions beneath the cloud cover, confidence in a surface value decreases proportionally to the length of the cloud cover persistence. As introduced by Hall et al. (2010), a piece of associated cloudpersistence information for each pixel is provided as an indicator of confidence in the actual pixel value. The cloud persistence values are low during clear conditions indicating high confidence and they increase with persisting cloudy conditions, resulting in lower confidence. Furthermore, for interpretation, one should consider that products based on gap filling methods only provide estimates of cloud-free observations of multiple days ( \pm 10 days) and pixel values remain subject to this uncertainty. Likewise, initial uncertainties arise from erroneous classification of clouds as snow and vice versa since the two features exhibit very similar spectral properties and remain difficult to discriminate. Based on this satellite-based snow cover climatology, the spatiotemporal distribution of snow in the Alps over the last two decades is analyzed with respect to spatial distribution, annual and inter-annual variations in snow cover. The time period considered for each application is indicated.

\subsection{Spatial distribution of snow cover (1991-2011)}

The long-term annual means (1991-2011) for the parameters SCD, SCOD and SCMD for the Alpine region are displayed in Fig. 5 for each AVHRR pixel. The overall uncertainty lies at \pm 10 days as reported in Sect. 4.1. Generally, altitude is the main influencing factor due to the temperature gradient decreasing with height. All parameters clearly follow the distinct topography. Focussing on SCD (Fig. 5, left panel), the highest areas are shown in dark red indicating year-round (365 days) snow cover above approximately $2900 \mathrm{~m}$ a.s.1. The SCD gradually decreases along the altitudinal steps and reaches a minimum of $<25$ days in the lowest regions in the south-west as well as in the south towards the Po Valley in Northern Italy. Similarly, regional differences become apparent. For example, the SCD in the south-western parts is much lower (i.e., 40 days on average) than in the north-eastern part (i.e., 75 days on average), even though lying at about the same altitude range (i.e., between 600 and $700 \mathrm{~m}$ a.s.1.). This occurs presumably due to different climatic influences (see Sect. 2). Yet, these regional differences decrease toward higher altitudes and the SCD becomes similar in magnitude in all regions.

Since the SCD is closely linked - at least in altitudes with stable snow cover - to the SCOD, when snow starts to accumulate, and to the SCMD, when snow disappears, a similar 

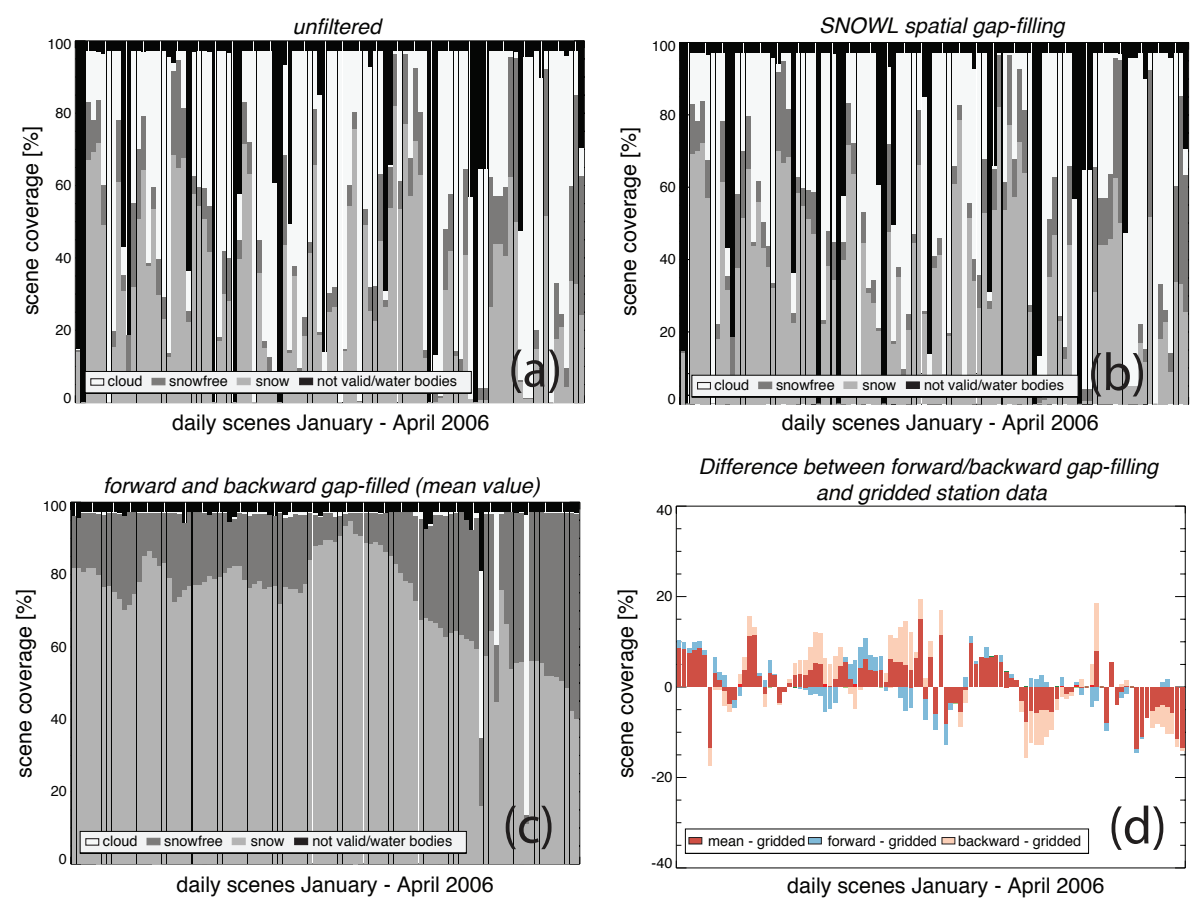

Fig. 3. Stepwise results from the spatial and temporal cloud removal process for the period January-April 2006: respective area percentage of Switzerland for the classes snow, snow free, cloud and not valid for (a) unfiltered scenes, (b) after SNOWL spatial gap-filling filter, (c) after temporal backward and forward gap-filling (mean value), (d) differences between forward and backward direction and averaged value thereof (calculated as the mean between the SCA value from the forward gap-filled product and the SCA value from the backward gap-filled product for the same day) and gridded station data.

Table 2. Quantitative assessment of classification redistribution after each type of filtering according to Fig. 3.

\begin{tabular}{clrrrrr}
\hline & & Min $(\%)$ & Lower quartile $(\%)$ & Median (\%) & Upper quartile (\%) & Max $(\%)$ \\
\hline \multirow{2}{*}{ Cloud } & no filter & 0.0 & 12.6 & 37.2 & 65.2 & 97.0 \\
& spatial filter & 0.0 & 14.0 & 35.7 & 61.0 & 97.0 \\
& temporal filter & 0.0 & 0.0 & 0.1 & 0.4 & 0.9 \\
\hline \multirow{2}{*}{ No data } & no filter & 0.0 & 3.0 & 3.0 & 6.4 & 10.3 \\
& spatial filter & 2.9 & 3.0 & 3.0 & 7.0 & 10.3 \\
& temporal filter & 2.9 & 2.9 & 2.9 & 3.0 & 3.0 \\
\hline \multirow{2}{*}{ Snow } & no filter & 0.0 & 6.2 & 26.3 & 51.2 & 81.9 \\
& spatial filter & 0.0 & 11.3 & 33.9 & 53.3 & 82.0 \\
& temporal filter & 40.0 & 62.9 & 76.7 & 82.2 & 94.6 \\
& snow gridded & 53.9 & 68.2 & 73.0 & 78.1 & 92.6 \\
\hline \multirow{2}{*}{ Snow free } & no filter & 0.0 & 1.5 & 5.5 & 14.1 & 29.8 \\
& spatial filter & 0.0 & 1.5 & 5.2 & 13.6 & 28.2 \\
& temporal filter & 2.4 & 14.2 & 19.3 & 31.8 & 56.7 \\
\hline
\end{tabular}

pattern can be found in the center and right panels of Fig. 5 . Even though the topography clearly emerges in both maps, regional differences such as the west-east as well as southnorth gradient are present. A comparatively more blurred pattern is observed in the SCOD map as this measure depends not only on temperature but also on availability of precipitable water in atmosphere. The SCMD, in contrast, shows very subtle differences indicating a slow and gradual decrease of snow between January (with values between 25 and 59 at low altitudes) and the end of May (at altitudes of around $2300 \mathrm{~m}$ a.s.l.; values of 225-244) caused by the spring temperature increase. These results are perfectly in line with observations made by Jonas et al. (2008) illustrating that SCOD 

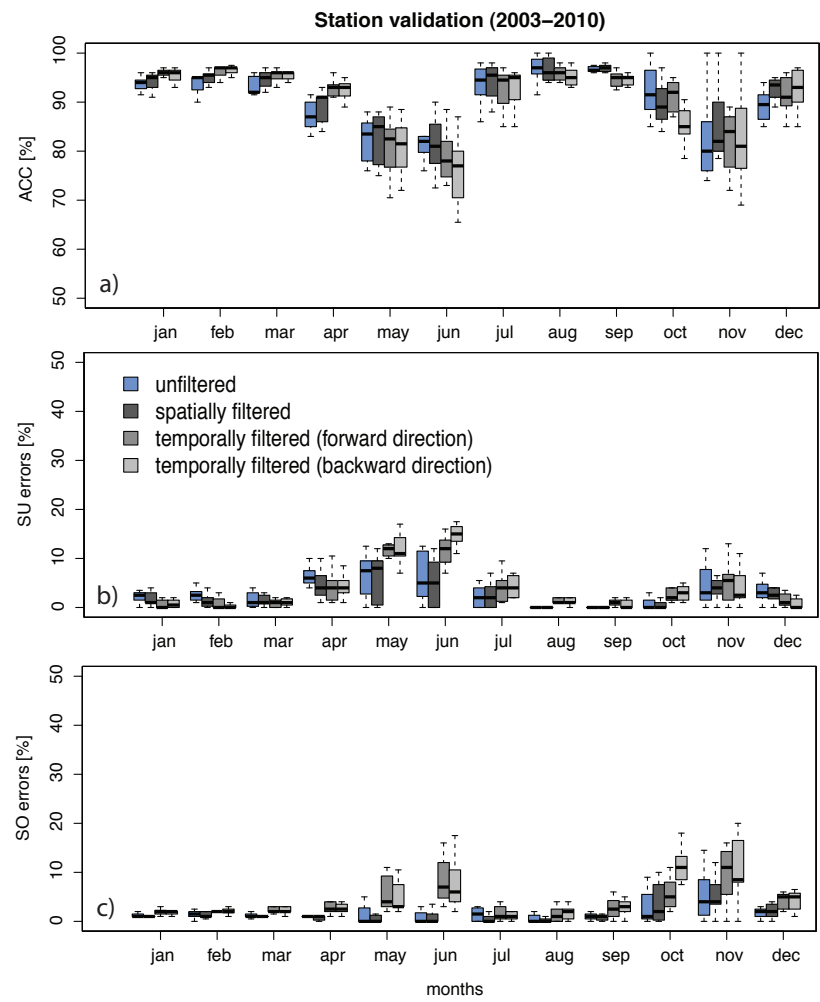

Fig. 4. Monthly median and Inter Quartile Range (IQR) of (a) ACC, (b) SU error, and (c) SO error from station validation for the period 2003-2010. Different colors refer to different types of filtering procedures (see legend).

(SCMD) shows little (high) correlation with elevation over time.

Figure 6 displays the SCD as a function of altitude and was calculated from all the pixel information available per $100 \mathrm{~m}$ altitude in the respective region. As expected, a clear positive relation between altitude and SCD is found with an increase of ca. 10 days per $100 \mathrm{~m}$ a.s.l. with a standard deviation of 25 days. This relationship, however, seems to depend on the climatic region. While in the southern regions exhibit constantly lower SCD at elevations up to $2200 \mathrm{~m}$, the northern regions show above-average SCD at the same altitudes. It is also remarkable that the regional differences are more pronounced at lower elevations and tend to disappear towards the high elevations. The same behavior is also found in the standard deviations. This may imply a higher sensitivity of SCD on temperature at lower regions and a stronger dependency of SCD on precipitation at the higher elevations.

\subsection{Annual variation of snow cover (1985-2011)}

The amount of snow present in the Alps varies considerably over the course of one year. The seasonal snow cover generally starts to increase in November, reaches a maximum between January and February and starts to melt out in mid-
March. By the end of May, almost all snow has disappeared except for the very high areas lying above $2500 \mathrm{~m}$ a.s.l.

Figure 7 quantitatively illustrates the monthly statistics, derived as median value of all the available daily scenes of a respective month, averaged over the period 1985-2011 retrieved from the satellite record. Focussing on the entire Alpine region, the snow cover peaks in January and February with a monthly median of $68 \%$, that corresponds to an area of approximately $155000 \mathrm{~km}^{2}$. During the melting season, it gradually decreases, reaching a minimum extent during August and September, when only the perennial snow and ice remain on the ground (approximately $2600 \mathrm{~km}^{2} \pm 25 \%$ in the Alps according to Fontana et al., 2010). The (IQR) is largest in February, March and November, when the highest inter-annual variability is observed due to variations of SCA in the transition zone (approximately $700-2100 \mathrm{~m}$ a.s.1.). As expected, the smallest variation is found during summer when a minimum snow cover is present, which is reasonably stable over the whole record's period.

Even though the subregions are not comparable in terms of absolute numbers as the altitude distribution is quite different (see Table 1), the qualitative annual snow cycle for each region can be seen from Fig. 7. Besides the general annual behavior, the subregions exhibit some interesting features: the north-western part of the Alps shows constantly higher values of SCA due to higher elevations while the south-western part (comparable in terms of altitudinal distribution) shows lower values in winter and relatively high values starting in April. The SCA decrease in the south-west and north-west, hosting the highest elevations, however, seems to be slightly slower than in the eastern regions by virtue of the melting process being decelerated as elevation increases. Obviously, the snow persistence varies in different elevations as onset of snow melt is naturally postponed with increases in the terrain elevation. Generally, the spread is highest from November through March but it varies among the four regions: the interannual variability in the north-west and south-west seems to be least pronounced (e.g., $10 \%$ in the north-west in January) resulting in a lower IQR than in the eastern regions (e.g., $20 \%$ in the north-east in January).

\subsection{Inter-annual variation of snow cover (1991-2011)}

In this section, we focus on the year-to-year variability of the snow cover, as it has repeatedly been shown to be considerable (Scherrer et al., 2004). The annual pixel-wise departures from the long-term mean (1991-2011) are displayed in Fig. 8 for the entire Alpine region. The highest regions (> 2900 ma.s.l.) in the Central Alps exhibit stable snow cover and the anomalies constantly lie within the uncertainty range of \pm 10 days. It can be further assumed that the SCD in the years 1998, 2002 and 2003 was below average, with 2007 being the poorest winter on record. In contrast, comprehensive above-average snow cover conditions are found in 1992, 1993, 2009 and 2010. 

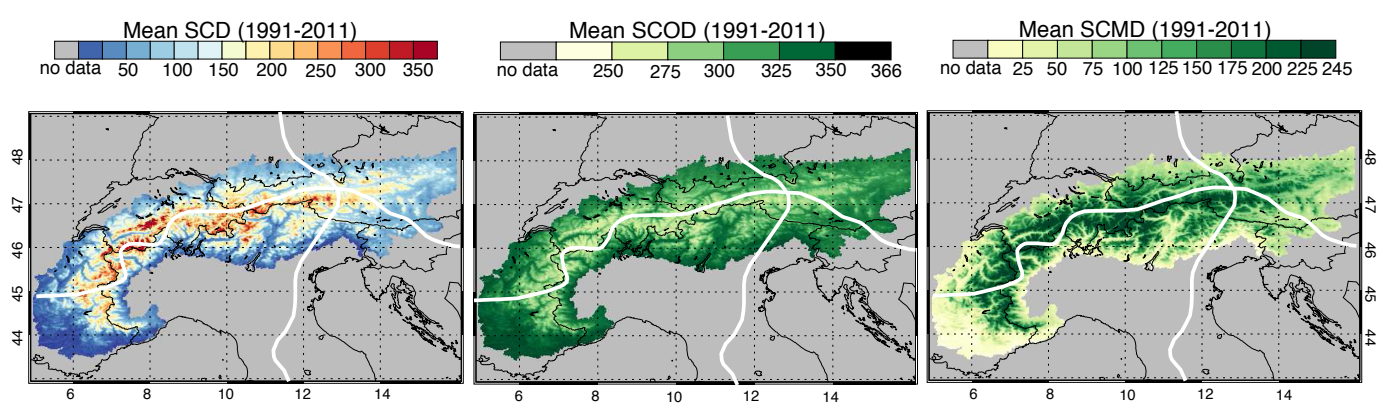

Fig. 5. Spatial representation of the long-term annual mean of snow cover parameters for the Alpine region (1991-2011): SCD (left) in numbers of snow days, SCOD (center) and SCMD (right), given as DOY for each pixel. Overall, a very strong correlation to the topography is observed but regional differences also become apparent. White lines indicate the climatic regions described in Sect. 2.

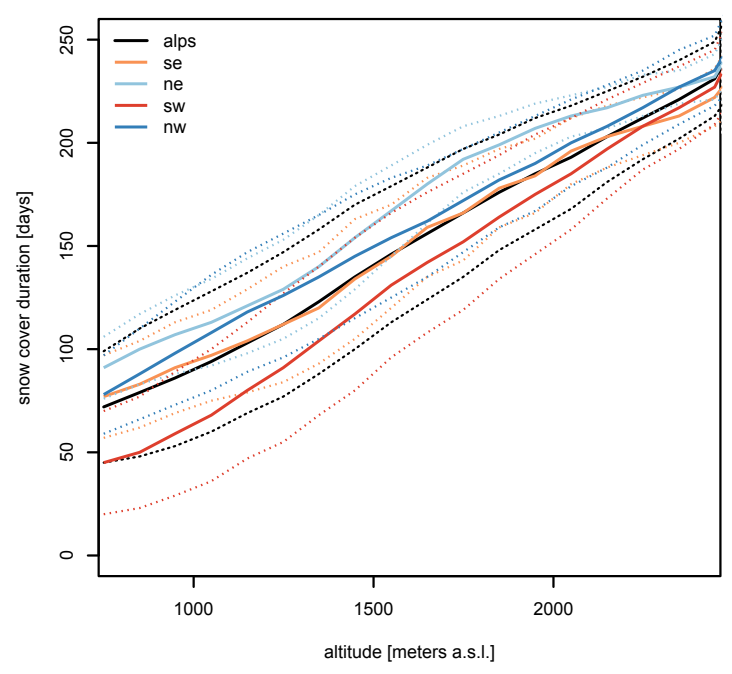

Fig. 6. SCD as a function of altitude for the Alps and the four regions separately. Bold lines represent the altitude mean SCD while the dotted lines indicate the standard deviation. The analysis was done at elevation steps of $100 \mathrm{~m}$.

It is striking that some anomaly patterns seem to occur systematically: firstly, a uniform pattern with above- (below-) average snow conditions, which prevails over the entire Alps (e.g., 1992, 1998, 2002 and 2007). Secondly, a pronounced north-south pattern can be observed in 1991, 1994 and 2005 when the Alpine ridge roughly divides the anomalies in a positive and a negative region. A third pattern follows an altitudinal gradient, for example, in 2003, 2006, 2008 and 2009. Lower levels clearly show below- (above-)average conditions while the higher altitudinal levels approach average conditions. Fourth, an east-west pattern, characterized by a meridional anomaly gradient, is presumed in 1996, 2000, 2004 and 2010.

Hence, the regions and altitudes were investigated in more detail as the varying climatic features seem to have a major influence on the snow cover distribution. Figure 9 illustrates the annual departures from the 1991-2011 median value (as it does not follow a normal distribution) for the three parameters SCD, SCOD and SCMD for each region with an altitudinal resolution of $100 \mathrm{~m}$ (from 700 to $2500 \mathrm{~m}$, which corresponds to the altitude levels experiencing seasonal snow cover). Generally it can be observed, that the altitudinal variation is more pronounced in SCMD while the variability in the snow onset is lower between different altitudes. The year-to-year variability though, was found to be higher in the SCOD for all altitudes as concluded from the IQR plot (figure not shown) where the spread for SCOD was much larger than for SCMD.

A closer look at the altitudinal distribution of variation reveals that the variability at lower regions (displayed in bluish colors in Fig. 9) is increased in comparison to the values of higher altitudes (red colors). This again implies the strong dependency of snow cover variation on the vertical temperature gradient as the likelihood of frequent transitions over freezing point is highest at lower elevations.

Regarding the inter-regional differences, some interesting features become visible. Besides the lower altitudes, the inter-annual spatial variations are more apparent in the southern regions of the Alps, where the SCD and SCMD parameters especially show a higher spread in the higher regions (i.e., south-west and south-east in 2002 and 2010). Furthermore, the pronounced anomalies in the lower regions (+40 days SCD) in 1996 only affected the eastern part of the Alps. The pattern of comparatively (short) long SCD at (higher) lower altitudes in 2006 is assumed to be caused by a late snow onset (at all altitudes) and repeated snowfall events in February and March (Stucki et al., 2011). These led to record snow amounts also at lower altitudes which lasted longer and delayed the melt-out day in spring 2006. In the case of 1998, all regions show increased negative lowaltitude anomalies and positive high-altitude anomalies, except for the south-eastern parts.

As these annual values are not affected by a cyclic (seasonal) pattern and no significant autocorrelation has been found, simple linear trends were estimated and tested for significance for each altitudinal range and each region. Most 


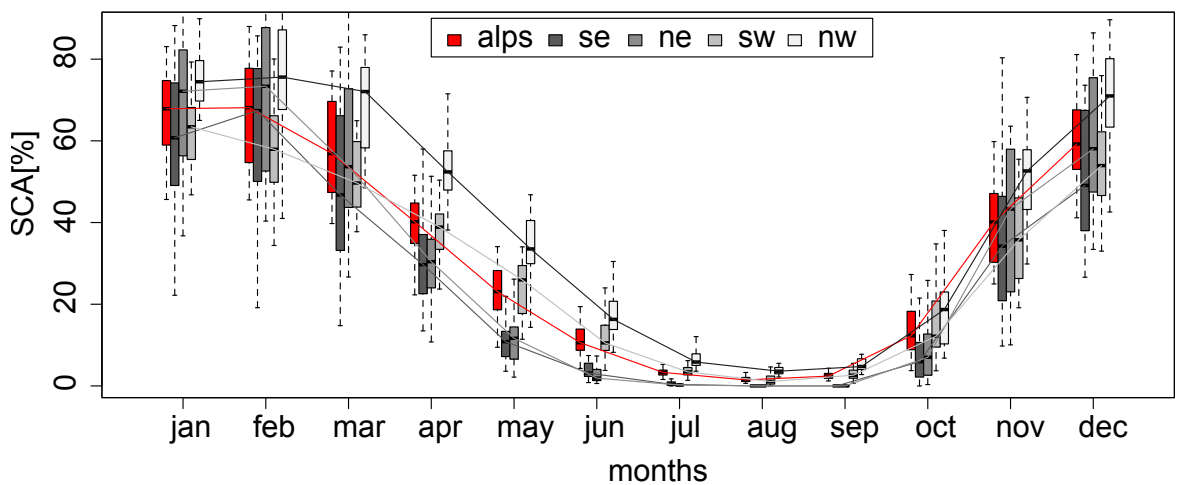

Fig. 7. Monthly median and IQR of SCA averaged over the period 1985-2011 for the whole Alpine region (red) and all four subregions (gray tones) over the course of the year. SCA values are given in numbers relative to the size of the respective region (cf. Table 1). To facilitate interpretation, lines connect median values from each month.

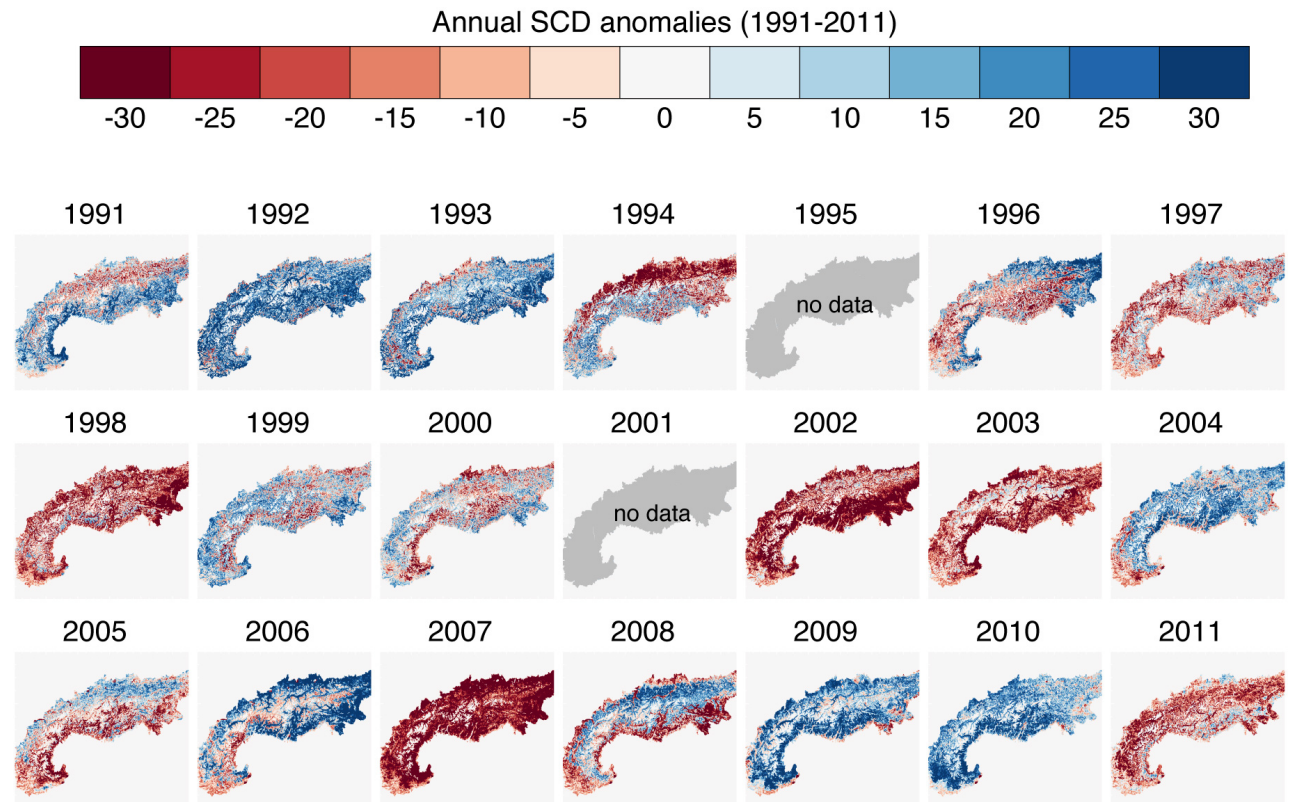

Fig. 8. Annual departures from the long-term mean (1991-2011) given in days. Years refer to 1 January. The data coverage in 1995 and 2001 was insufficient for the application.

of them showed a decreasing tendency but were found to be insignificant, including the trends for the Alpine region as a whole. For some particular altitudes in single regions, however, evidence for decreasing (or increasing) values was found. These mostly affected the lowest (and partially also the highest) altitudes in the southern regions: for SCD, a slight evidence against the null hypothesis $(0.05<p<0.1)$ was found in SW at alti-

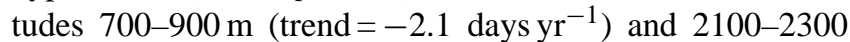

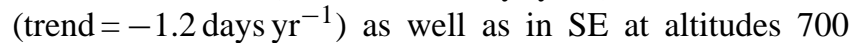
and 800 (trend $=-1.7 /-1.8$ days $\mathrm{yr}^{-1}$ ). Concerning SCOD, slight evidence for a later snow onset was also found in the lowest (900-1100) and highest altitude (2100-2300) levels in SW and SE. For altitudes 700-900, even moderate ev- idence $(p<0.05)$ was found, implying a significant trend of +0.9 days $\mathrm{yr}^{-1}$. Also for the SE, significant trends $(p<$ $0.05)$ toward a later snow onset in the lower altitudes (7001200 ) were found (with trends around +1 day $\mathrm{yr}^{-1}$ ). In summary and even though the time series is comparatively short, the lowest regions of the southern Alps seem to be the most affected by climate change over the last $20 \mathrm{yr}$ while the changes in northern and more elevated parts do not show any significant tendency.

\subsection{Time series of SCA (1985-2011)}

Finally, an SCA time series analysis based on monthly data was carried out. To demonstrate the temporal stability of the 


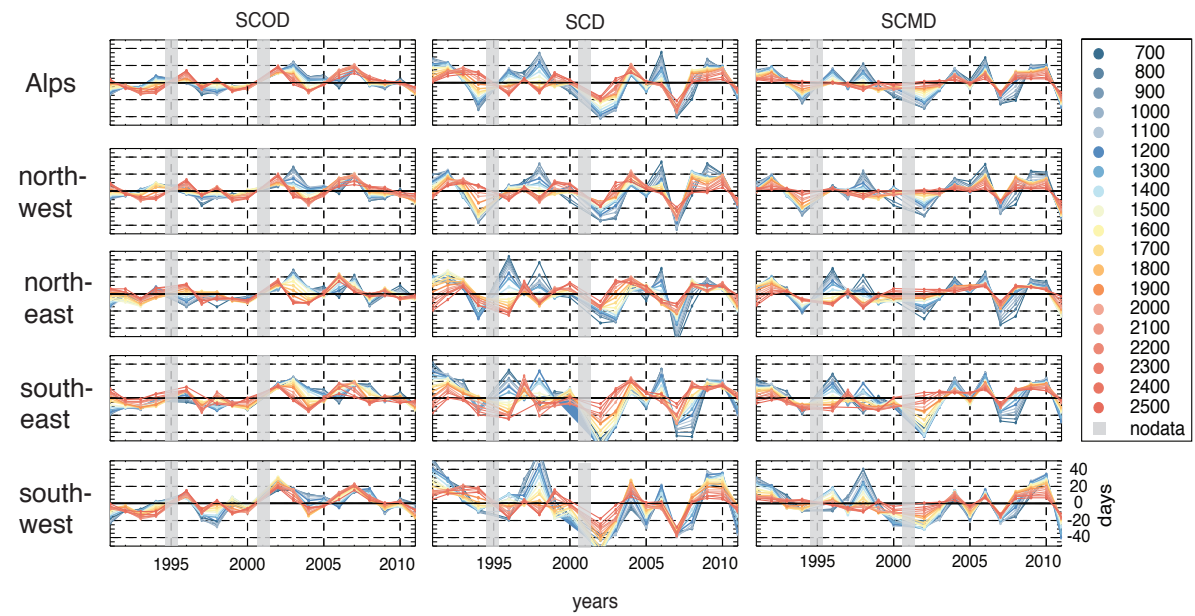

Fig. 9. Annual departures (1991-2011) of SCOD, SCD and SCMD from the long-term median for the Alpine region and all subregions given in days for different altitude levels. Years refer to 1 January. Connecting lines are displayed for easier readability of the figure only. The data coverage in 1995 and 2001 was insufficient for the application.

SCA data set derived from several generations of AVHRR sensors, monthly mean values from the satellite-derived SCA were compared to the same variable derived from the gridded station data set (available December-May, 1989-2009, for Switzerland). The results are displayed in Fig. 10. A high consistency is found, not only for the relative dynamic of the SCA, but also for the absolute numbers of monthly mean values, especially in the years after 2001. The satellite record even captures small features such as the two SCA peaks in the winters 1991, 2007 or 2008. A slight overestimation of satellite-derived SCA compared to ground SCA is found in 1992 and 1993, however, and in 1995 and 1999 the satellite SCA seems not to resolve the highest peaks in January and February. In 1990, the real snow cover onset is found to be somewhat shifted to earlier dates in the satellite data but the absolute numbers of the winter maximum, lying at $50 \%$, are well represented.

The irregular distribution of AVHRR data (cf. Fig. 2) needs special attention before time series analysis. Therefore, we tested whether the increasing availability of scenes influences the accuracy of the monthly values. This was done by artificially reducing the number of scenes in 2002-2011 to the level of 1990-2000 when only one satellite was in orbit at a time. The obtained monthly mean values are over-plotted in red in the upper graph and the absolute differences between the two data sets are shown in the lower graph in Fig. 10. Except for three outliers, $95 \%$ of the values lie within $\pm 6 \%$. Overall, the monthly mean values do not significantly differ ( $t$ tested, $p=0.8$ ). The mean difference lies at $1.1 \%$ with a standard deviation of $3.6 \%$. Therefore, it is concluded that the data distribution does not have an essential influence on the derived snow climatology. In addition, we hypothesize that the slightly advanced sensor technology of AVHRR/3, operating on N16 to N19 from 2002 onwards, rather than the data disposability, is responsible for the high agreement with the ground data in Fig. 10 after 2002.

Having assessed the accuracy and consistency of the satellite record, a $27 \mathrm{yr}$ time series of SCA was compiled and analyzed for the whole extent of the Alpine region. As missing values were inevitable due to satellite data unavailability, data gaps (namely three months in 1995 and four months in 2001) were filled by the long-term mean value of the respective months. The pronounced seasonal cycle of snow cover (see also Fig. 10) was removed by using the monthly standardized anomalies.

It has been shown that the precision of trend estimates in environmental data is critically influenced by the variability and autocorrelation of the underlying noise process (Tiao et al., 1990). In particular, autocorrelation tends to interact with the linear trend and therefore increases the length of the time series required to detect a certain trend (Weatherhead et al., 1998). The necessary length of record (monthly data) can therefore be assessed by investigating the standard deviation and the autocorrelation of the residuals after the seasonal component has been removed (i.e., the standardized anomalies).

As expected, the autocorrelation of the time series (residuals) is significant ( $>0.5$ lag-1) and the standard deviation of the residuals is $\sigma=7.9$. Applying the Eq. (3) in Weatherhead et al. (1998), we calculated the number of years of data required to detect a real trend of a certain magnitude. Using the autocorrelation and variation of the time series residuals, this results in a minimum length of time period of $21 \mathrm{yr}$ to detect a significant trend of the magnitude of $5 \%$ per decade. A time period of approximately $61 \mathrm{yr}$ would be required to detect a less strong but significant trend of $1 \%$ per decade (always at a $90 \%$ confidence level) for the SCA parameter. Therefore, we conclude, that (depending on the magnitude 


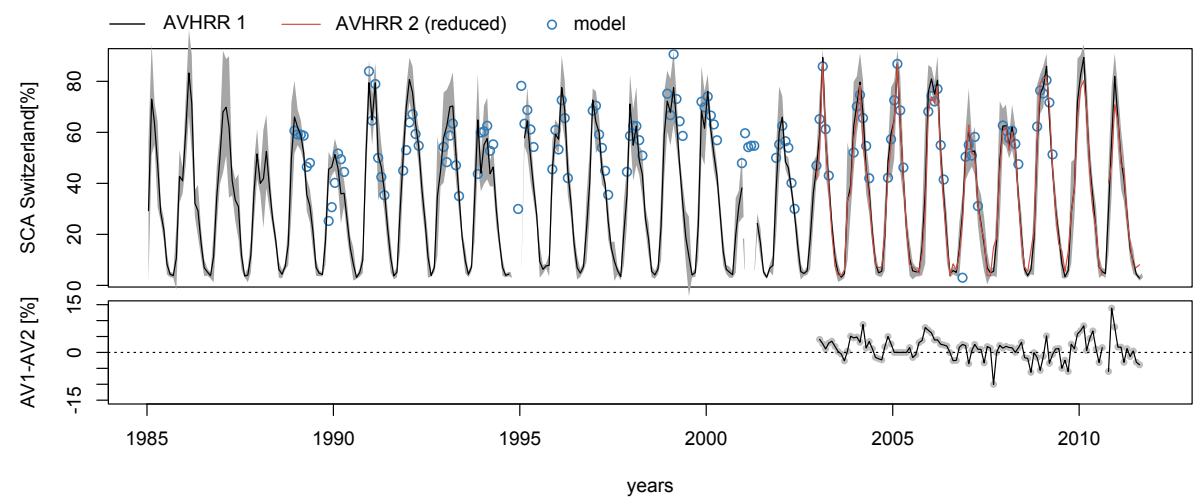

Fig. 10. Time series (1985-2011) of monthly values of SCA for Switzerland (AVHRR 1; black) including monthly standard deviation (gray shaded area) compared to the same measures derived from gridded station data (blue dots). AVHRR 2 (red) displays the snow cover data set with reduced number of scenes. Differences between the full data set (AVHRR 1) and the artificially reduced data set (AVHRR 2) are illustrated in the lower graph.

Table 3. Regression parameters trend $\omega$ per decade, $p$ value, autocorrelation $\varphi$ at lag-1 and standard deviation of the residuals $\sigma$ for the SCA standardized anomaly time series illustrated in Figs. 11 and 12 .

\begin{tabular}{lrrrr}
\hline Region & $\omega /$ decade $[$ SD] & $p$ value & $\varphi$ & $\sigma$ \\
\hline Alps & 0.02 & 0.77 & 0.55 & 7.9 \\
NE & 0.08 & 0.21 & 0.36 & 11.13 \\
NW & 0.08 & 0.23 & 0.45 & 8.26 \\
SE & 0.03 & 0.62 & 0.49 & 11.17 \\
SW & -0.04 & 0.55 & 0.50 & 7.77 \\
\hline
\end{tabular}

of trend) the time series should be analyzed for trends with care.

Figure 11 illustrates the monthly SCA standardized anomalies derived from the satellite record over the European Alps (1985-2011). The respective regression parameters and the autocorrelation value are provided in Table 3 . As has been observed in Fig. 8, the years 1988-1990, 2002 and 2007 are extreme with a relatively small SCA. On the contrary, the years 1991, 1992, 2005, 2009 and 2010 represent years with relatively high SCA values. Concerning the Alpine region as a whole, no statistically significant trend $(p=0.7)$ in SCA over the last $27 \mathrm{yr}$ was found in annual SCA in the Alpine region.

To revisit the regional issue, the same analysis was carried out for all subregions (the absolute SCA time series for each region are plotted in Fig. A1). The standardized monthly anomalies are illustrated in Fig. 12. No significant trends were found here either, as can be seen from Table 3, which summarizes the regression parameters and the autocorrelation values for each region separately. Slight differences in the anomalies are still apparent between the subregions (e.g., in 1994 and 1996) and although not significant, the linear trend-lines tend towards increasing SCA in the northern parts and towards decreasing SCA in the southwestern region with a decadal trend of -0.04 standard deviations (cf. Table 3).

\section{General discussion}

The above findings generally indicate that alpine snow cover is highly variable in time and space. Due to its medium resolution of $1 \mathrm{~km}$, this record is not able to investigate small scale features such as snow line dependence on aspect as a pixel in complex terrain typically includes various aspects. Rather, it is intended to capture the relative large scale snow dynamics that seem to be well reproduced. Four patterns relating to spatial anomaly occurrence were suggested: uniform, altitudinal, meridional and zonal. On the regional scale, these patterns generally agree with the findings by Laternser and Schneebeli (2003) who presented three priorities on which the degree of snowiness in Switzerland is based: first (time) with periods of abundant or poor snow conditions spanning large areas. Due to the relative brevity of the record, this pattern is not as obvious here but presumably resembles the first pattern. Second (space) with distinct regions showing more or less pronounced anomalies such as the north-south pattern found here. And third (altitude) with relative differences in anomalies along altitudinal steps. Analogous patterns were also found by Scherrer and Appenzeller (2006). In their investigations, they identified three major patterns of large-scale snow variability for Switzerland (for the parameters December-January-February period new snow sum, snow depth and snow days): uniform, north-south and lowhigh altitude. However, both studies were restricted to the area of Switzerland, that is, they were located (as defined here) mostly in the north-west and minor parts in the southwest. Upon extending the analysis to the entire Alpine region, an east-west gradient also becomes apparent in this study. 


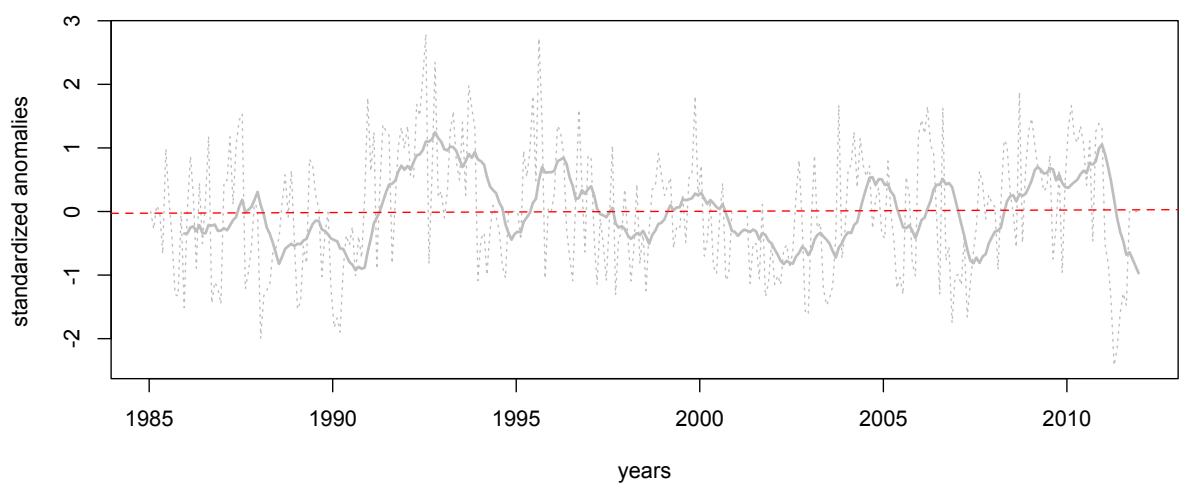

Fig. 11. Time series of Alpine region SCA monthly standardized anomalies derived from AVHRR data 1985-2011. The dotted line indicates the monthly values while the grey solid line depicts the 12-month standard moving average. The red line represents the respective linear trend.

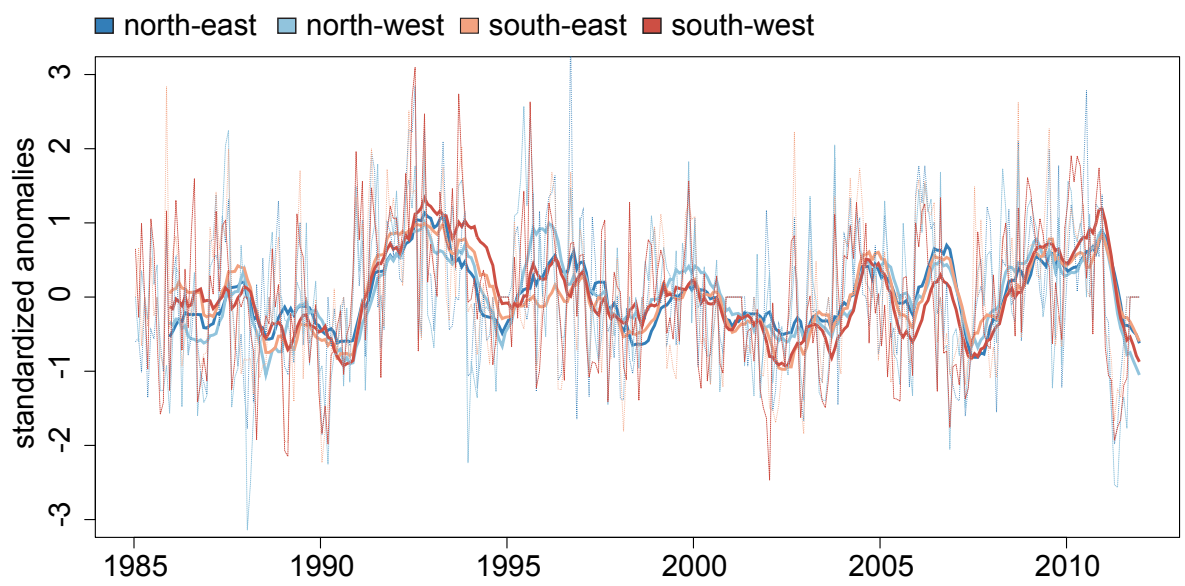

Fig. 12. Same as Fig. 11 but resolved into the four climatic regions.

The results obtained from the novel satellite-based SCA time series reveal interesting details on the temporal distribution of the snow cover extent in the Alpine region over the last $27 \mathrm{yr}$. Indeed, many long-term in situ snow climatologies in different regions have been analyzed investigating different snow parameters, generally showing a significant decrease of snow abundance (Marty, 2008; Beniston, 1997; EEA, 2009; Durand et al., 2009) particularly at lower altitudes. Most of them, however, analyze earlier periods or smaller areas than the record presented here. The 1990s were previously found to be the years with the lowest new snow sums and snow days on record (Laternser and Schneebeli, 2003), while the newest results show that the snow conditions seem to have partly recovered since 2000, especially at low elevations (Scherrer et al., 2010; Valt and Cianfarra, 2010). Recently, Scherrer et al. (2013) even showed that the strongly decreasing trends found in the late 1980s and 1990s are followed by a trend reversal in the last $10 \mathrm{yr}$ (2000-2009), which was attributed to a recent "plateauing" or even slightly decreasing temperatures in Switzerland.
Apparently, this behavior could be appropriately reproduced in the satellite record and seems to apply to the whole Alpine region. Furthermore, this may explain the absence of a significant trend in the standardized SCA anomalies. Therefore, our results do not conflict with previous findings but may also indicate - confirming the findings by Scherrer et al. (2013) - a deceleration of the decreasing snow trend in the Alpine region, even though the time period is comparatively short. Yet, indications towards a shorter SCD in lower regions in the southern parts were found.

Finally, on the hemispheric scale, the AVHRR snow time series is in good agreement with the satellite-based snow cover climatology of the Northern Hemisphere (NH) weekly updated at the Rutgers Snow Lab (http://climate.rutgers. edu/snowcover/; accessed March 2013). This climatology also suggests a weakening (even a reversal in the DJF) in the negative trend found for the period under investigation here. Unfortunately, the prominent abrupt shift in NH snow cover extent in the 1980s, described in Robinson and Frei (2000), lies beyond the length of this record. Nevertheless, 
the major advantage of this record, compared to similar products such as Moderate Resolution Imaging Spectroradiometer (MODIS) or (Advanced) Along-Track Scanning Radiometer ((A)ATSR), is its unique length. Likewise, the relatively high spatial resolution compared to existing longterm satellite records such as the Rutgers snow lab product $(24 \mathrm{~km})$ enables snow cover investigations even in complex terrain.

\section{Conclusions}

In this study, we presented a novel $1 \mathrm{~km}$ satellite-based snow cover data set for the Alpine region. The first objective was to generate a new set of cloud-free satellite snow products for use in climate research. This was done using a cloud gap-filling technique based on a combination of spatial and temporal compositing. Thereby, the amount of cloud could be substantially reduced and a comparison of the composite product with gridded station data suggests good accuracy. Furthermore, critical issues such as data record length or irregular data availability, potentially affecting the consistency and significance of the data set, were addressed. Based on the relation between the autocorrelation and the standard deviation of the residuals (see Weatherhead et al., 1998), the length of the recorded period is concluded to be sufficient for limited magnitudes of the trend for the SCA parameter. By artificially reducing the data availability to the level of one satellite in orbit at a time, it was shown that the values almost exactly coincide with the SCA derived from the full data set. Consequently, we assume data availability as having no essential influence on the SCA climatology. Yet, small data gaps, pixel misclassifications or cloud persistence longer than the filling period ( 10 days here) inevitably introduce minor errors in parameters such as SCOD, SCD or SCMD.

Based on this data set, the second objective was to investigate spatiotemporal distribution of snow cover in the European Alps over the last $27 \mathrm{yr}$ ( $21 \mathrm{yr}$ for spatial applications) from the satellite perspective. The long-term mean spatial representation of SCD, SCOD and SCMD showed a strong correlation of these parameters with altitude due to the vertical temperature gradient. However, regional differences became apparent, especially between the northern and the southern parts of the Alpine main crest, but also along the east-west direction. Similar patterns, namely uniform, altitudinal, meridional and zonal, were found in the annual departures of SCD from the long-term mean for the period 19912011. Regional analyses indicated significant trends towards shorter SCD at low elevations (700-900 m a.s.1.) in the southwest and south-east.
Overall, the analysis of the $27 \mathrm{yr}$ SCA monthly mean time series (1985-2011) indicated no significant linear trend for the entire Alpine region. The same is true for regional analyses even though some tendencies toward increasing (decreasing) SCD in the northern (southern) parts were found. Although this result is somewhat surprising in the context of an anticipated climate change, it is in accordance with other research findings.

As this study presents a broad overview on the spatiotemporal snow cover variability, it also implies the need for more detailed investigations. For example, future work could be directed towards seasonal trend analysis. It is also recommended to focus on large-scale atmospheric modes of climate variability (North Atlantic Oscillation or Arctic Oscillation), that were found to have a certain influence on European snow cover (Bartolini et al., 2010; Kim et al., 2012). In addition, the use of a simple degree-day approach or the zerodegree isotherm might be included in the analysis to discern the influence of temperature and precipitation on snow cover variability. Furthermore, the SCMD data may feature an interesting bridge to the analysis of future alpine plant growth as this parameter was found to be highly correlated to the timing of snow melt out (Rammig et al., 2010).

Following the above considerations, these results establish the confidence in RS products for the purpose of long-term snow applications as we succeeded in (a) suppressing the influence of changing sensors and increasing data availability and (b) the gap filling methods seem to work well. Both, (a) and (b) raise confidence in the data set and demonstrate the valuable role of a long-term satellite-based snow climatology for complementing in situ time series. This study is therefore considered an important contribution to a regional climate observing system. Basically, the methodology used to compile this data set could be applied to other regions of the world with sparser ground data than the Alpine region. Nevertheless, this critically depends on the availability of longterm AVHRR archives at the sensor's full spatial resolution. An extension of the data set to cover whole Europe is planned within the scope of the Globsnow-2 project funded by the European Space Agency (ESA). Finally, this novel data record bears the potential to serve as a reference for climate models, in which snow cover is still not adequately represented, and to provide spatially and temporally comprehensive information for related research fields. 


\section{Appendix A}

Fig. A1 Time series (1985-2011) of absolute monthly values of SCA for each region including monthly standard deviation (gray shaded area).
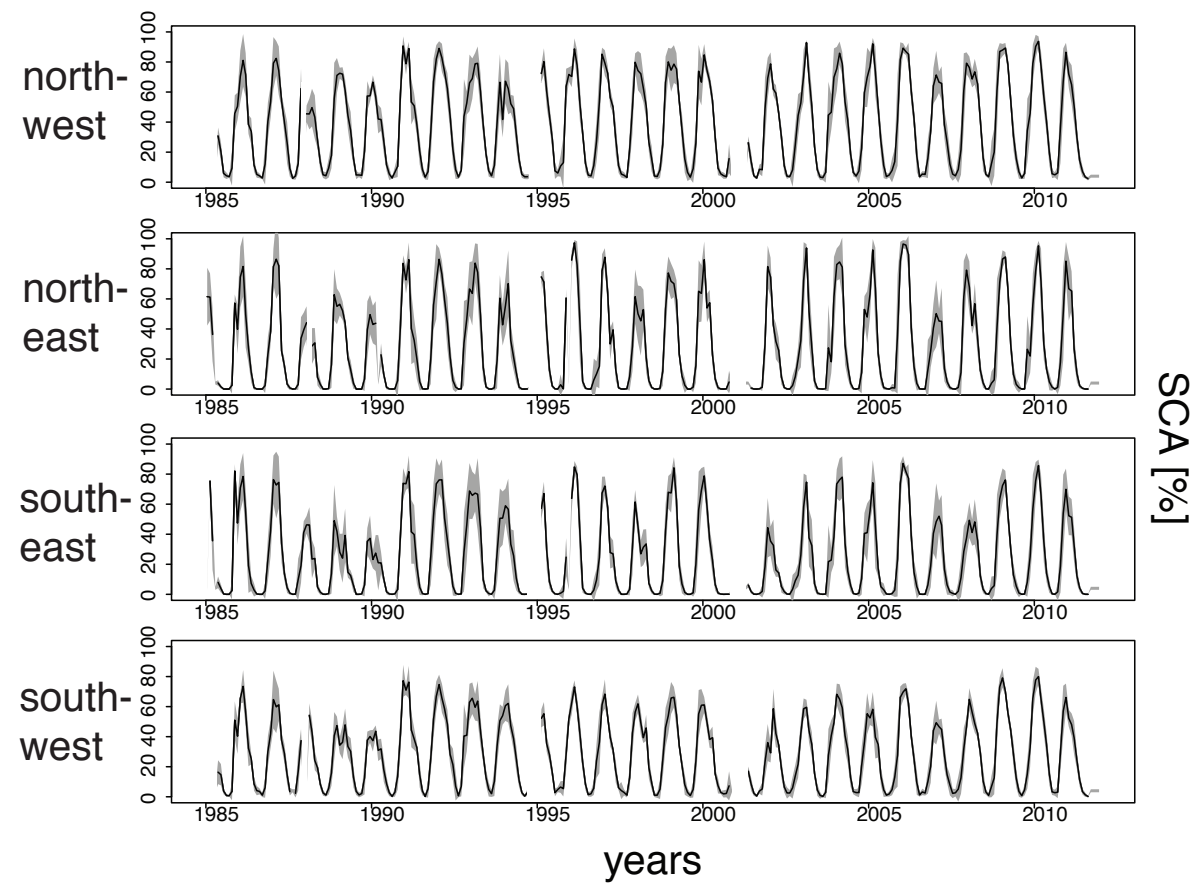

Acknowledgements. The AVHRR $1 \mathrm{~km}$ data were partially acquired from the NOAA Comprehensive Large Array-data Stewardship System (CLASS; http://www.nsof.class.noaa.gov), the German Aerospace Center (DLR) and the Freie Universität Berlin. Special thanks go to D. Koslowsky. We acknowledge the E-OBS data set from the EU-FP6 project ENSEMBLES and the data providers in the ECA \& D project (http://www.ecad.eu). The authors wish to express their gratitude to R. Armstrong and N. Foppa for their valuable inputs on the manuscript. This work was funded by the Hyper-Swiss-Net and the ESA Globsnow-2 project.

Edited by: D. Hall

\section{References}

Agrawala, S.: Climate change in the European Alps: adapting winter tourism and natural hazards management, Organisation for Economic Co-operation and Development, 2007.

Armstrong, R. L. and Brodzik, M. J.: Recent Northern Hemisphere snow extent: A comparison of data derived from visible and microwave satellite sensors, Geophys. Res. Lett., 28, 3673-3676, 2001.

Auer, I., Böhm, R., Jurkovic, A., Lipa, W., Orlik, A., Potzmann, R., Schöner, W., Ungersböck, M., Matulla, C., Briffa, K., Jones, P., Efthymiadis, D., Brunetti, M., Nanni, T., Maugeri, M., Mercalli, L., Mestre, O., Moisselin, J.-M., Begert, M., MüllerWestermeier, G., Kveton, V., Bochnicek, O., Stastny, P., Lapin, M., Szalai, S., Szentimrey, T., Cegnar, T., Dolinar, M., GajicCapka, M., Zaninovic, K., Majstorovic, Z., and Nieplova, E.:
HISTALP-historical instrumental climatological surface time series of the Greater Alpine Region, Int. J. Climatol., 27, 17-46, doi:10.1002/joc.1377, 2007.

Auer, M., Meister, R., Stoffel, A., and Weingartner, R.: Analyse und Darstellung der mittleren monatlichen Schneehöhen in der Schweiz, Wasser Energ. Luft, 96 (7/8), 173-178, 2004.

Bartolini, E., Claps, P., and D'Odorico, P.: Connecting European snow cover variability with large scale atmospheric patterns, Adv. Geosci., 26, 93-97, doi:10.5194/adgeo-26-93-2010, 2010.

Beniston, M.: Variations of snow depth and duration in the Swiss Alps over the last 50 years: links to changes in large-scale climatic forcings, Clim. Change, 36, 281-300, 1997.

Cihlar, J., Latifovic, R., Chena, J., Trishchenko, A., Duc, Y., Fedosejevsa, G., and Guindona, B.: Systematic corrections of AVHRR image composites for temporal studies, Remote Sens. Environ., 89, 217-233, doi:10.1016/j.rse.2002.06.007, 2004.

Dietz, A. J., Kuenzer, C., Gessner, U., and Dech, S.: Remote sensing of snow - a review of available methods, Int. J. Remote Sens., 33, 4094-4134, doi:10.1080/01431161.2011.640964, 2012.

Durand, Y., Giraud, G., Laternser, M., Etchevers, P., Mérindol, L., and Lesaffre, B.: Reanalysis of 47 Years of Climate in the French Alps (1958-2005): Climatology and Trends for Snow Cover, J. Appl. Meteorol. Clim., 48, 2487-2512, doi:10.1175/2009JAMC1810.1, 2009.

EEA: Regional climate change and adaptation, Tech. rep., European Environmental Agency, doi:10.2800/12552, Copenhagen, 2009.

Elsasser, H. and Bürki, R.: Climate change as a threat to tourism in the Alps, Clim. Res., 20, 253-257, doi:10.3354/cr020253, 2002. 
Fontana, F. M. A., Trishchenko, A. P., Luo, Y., Khlopenkov, K. V., Nussbaumer, S. U., and Wunderle, S.: Perennial snow and ice variations (2000-2008) in the Arctic circumpolar land area from satellite observations, J. Geophys. Res., 115, F04020, doi:10.1029/2010JF001664, 2010.

Foppa, N. and Seiz, G.: Inter-annual variations of snow days over Switzerland from 2000-2010 derived from MODIS satellite data, The Cryosphere, 6, 331-342, doi:10.5194/tc-6-331-2012, 2012.

Fuchs, S. and Brandl, M.: Damage Potential and Losses Resulting from Snow Avalanches in Settlements of the Canton of Grisons, Switzerland, Nat. Hazards, 34, 53-69, doi:10.1007/s11069-0040784-y, 2005.

Gafurov, A. and Bárdossy, A.: Cloud removal methodology from MODIS snow cover product, Hydrol. Earth Syst. Sci., 13, 13611373, doi:10.5194/hess-13-1361-2009, 2009.

Gao, J., Williams, M. W., Fu, X., and Gong, T.: Spatiotemporal distribution of snow in eastern Tibet and the response to climate change, Remote Sens. Environ., 121, 1-9, doi:10.1016/j.rse.2012.01.006, 2012.

Gutman, G. and Masek, J. G.: Long-term time series of the Earth's land-surface observations from space, Int. J. Remote Sens., 33, 4700-4719, doi:10.1080/01431161.2011.638341, 2012.

Hall, D. K., Riggs, G. A., Foster, J. L., and Kumar, S. V.: Development and evaluation of a cloud-gap-filled MODIS daily snow-cover product, Remote Sens. Environ., 114, 496-503, doi:10.1016/j.rse.2009.10.007, 2010.

Hänggi, P. and Weingartner, R.: Variations in Discharge Volumes for Hydropower Generation in Switzerland, Water Resour. Manag., 26, 1231-1252, doi:10.1007/s11269-011-9956-1, 2012.

Hantel, M. and Hirtl-Wielke, L. M.: Sensitivity of Alpine snow cover to European temperature, Int. J. Climatol., 27, 1265-1275, doi:10.1002/joc.1472, 2007.

Haylock, M. R., Hofstra, N., Klein Tank, A. M. G., Klok, E. J., Jones, P. D., and New, M.: A European daily highresolution gridded data set of surface temperature and precipitation for 1950-2006, J. Geophys. Res., 113, D20119, doi:10.1029/2008JD010201, 2008.

Heidinger, A. K., Straka, W. C., Molling, C. C., Sullivan, J. T., and Wu, X. Q.: Deriving an inter-sensor consistent calibration for the AVHRR solar reflectance data record, Int. J. Remote Sens., 31, 6493-6517, doi:10.1080/01431161.2010.496472, 2010.

Hosmer, D. W. and Lemeshow, S.: Applied logistic regression, Wiley series in probability and statistics: Texts and references section, Wiley, 2000.

Hüsler, F., Fontana, F., Riffler, M., Neuhaus, C., Musial, J., and Wunderle, S.: AVHRR Archive and Processing Facility at the University of Bern: A Comprehensive 1-km Satellite Data Set for Climate Change Studies, EARSeL eProc, 10, 83-101, 2011.

Hüsler, F., Jonas, T., Wunderle, S., and Albrecht, S.: Validation of a modified snow cover retrieval algorithm from historical 1-km AVHRR data over the European Alps, Remote Sens. Environ., 121, 497-515, doi:10.1016/j.rse.2012.02.018, 2012.

IPCC: Climate Change 2007: The Physical Science Basis, Tech. rep., Intergovernmental Panel on Climate Change (IPCC), Geneva, Switzerland, 2007.

James, M. E. and Kalluri, S. N.: The Pathfinder AVHRR land data set: An improved coarse resolution data set for terrestrial monitoring, Int. J. Remote Sens., 15, 3347-3363, 1994.
Jasper, K., Gurtz, J., and Lang, H.: Advanced flood forecasting in Alpine watersheds by coupling meteorological observations and forecasts with a distributed hydrological model, J. Hydrol., 267, 40-52, doi:10.1016/S0022-1694(02)00138-5, 2002.

Jonas, T., Rixen, C., Sturm, M., and Stöckli, V.: How alpine plant growth is linked to snow cover and climate variability, J. Geophys. Res.-Biogeo., 113, G03013, doi:10.1029/2007JG000680, 2008.

Jonas, T., Marty, C., and Magnusson, J.: Estimating the snow water equivalent from snow depth measurements in the Swiss Alps, J. Hydrol., 378, 161-167, doi:10.1016/j.jhydrol.2009.09.021, 2009.

Jones, J.: Habitat selection studies in avian ecology: a critical review, The Auk, 118, 557-562, 2001.

Khlopenkov, K. V. and Trishchenko, A. P.: SPARC: New cloud, snow, and cloud shadow detection scheme for historical 1-km AVHRR data over Canada, J. Atmos. Ocean. Tech., 24, 322-343, 2007.

Kim, Y., Kim, K.-Y., and Kim, B.-M.: Physical mechanisms of European winter snow cover variability and its relationship to the NAO, Clim. Dynam., 40, 1657-1669, doi:10.1007/s00382-0121365-5, 2012.

König, M., Winther, J.-G., and Isaksson, E.: Measuring snow and glacier ice properties from satellite, Rev. Geophys., 39, 1-27, doi:10.1029/1999RG000076, 2001.

Laternser, M. and Schneebeli, M.: Long-term snow climate trends of the Swiss Alps (1931-99), Int. J. Climatol., 23, 733-750, 2003.

Lehning, M., Bartelt, P., Brown, B., Russi, T., Stockli, U., and Zimmerli, M.: SNOWPACK model calculations for avalanche warning based upon a new network of weather and snow stations, Cold Reg. Sci. Technol., 30, 145-157, 1999.

Lehning, M., Völksch, I., Gustafsson, D., Nguyen, T. A., Stähli, M., and Zappa, M.: ALPINE3D : a detailed model of mountain surface processes and its application to snow hydrology, Hydrol. Process., 20, 2111-2128, doi:10.1002/hyp.6204, 2006.

Magnusson, J., Farinotti, D., Jonas, T., and Bavay, M.: Quantitative evaluation of different hydrological modelling approaches in a partly glacierized Swiss watershed, Hydrol. Process., 25, 20712084, doi:10.1002/hyp.7958, 2011.

Marks, D., Domingo, J., Susong, D., Link, T., and Garen, D.: A spatially distributed energy balance snowmelt model for application in mountain basins, Hydrol. Process., 13, 1935-1959, doi:10.1002/(SICI)1099-1085(199909)13:12/13<1935::AIDHYP868>3.0.CO;2-C, 1999.

Marty, C.: Regime shift of snow days in Switzerland, Geophys. Res. Lett., 35, L12501, doi:10.1029/2008GL033998, 2008.

Marty, C. and Meister, R.: Long-term snow and weather observations at Weissfluhjoch and its relation to other high-altitude observatories in the Alps, Theor. Appl. Climatol., 110, 573-583, doi:10.1007/s00704-012-0584-3, 2012.

Metsämäki, S., Mattila, O.-P., Pulliainen, J., Niemi, K., Luojus, K., and Böttcher, K.: An optical reflectance modelbased method for fractional snow cover mapping applicable to continental scale, Remote Sens. Environ., 123, 508-521, doi:10.1016/j.rse.2012.04.010, 2012.

Nolin, A. W.: Recent advances in remote sensing of seasonal snow, J. Glaciol., 56, 1141-1150, doi:10.3189/002214311796406077, 2011. 
Parajka, J. and Blöschl, G.: Validation of MODIS snow cover images over Austria, Hydrol. Earth Syst. Sci., 10, 679-689, doi:10.5194/hess-10-679-2006, 2006.

Parajka, J. and Blöschl, G.: Spatio-temporal combination of MODIS images-potential for snow cover mapping, Water Resour. Res., 44, W03406, doi:10.1029/2007WR006204, 2008.

Parajka, J., Pepe, M., Rampini, A., Rossi, S., and Blöschl, G.: A regional snow-line method for estimating snow cover from MODIS during cloud cover, J. Hydrol., 381, 203-212, doi:10.1016/j.jhydrol.2009.11.042, 2010.

Rammig, A., Jonas, T., Zimmermann, N. E., and Rixen, C.: Changes in alpine plant growth under future climate conditions, Biogeosciences, 7, 2013-2024, doi:10.5194/bg-7-2013-2010, 2010.

Rango, A. and Martinec, J.: Revisiting the degree-day method for snowmelt computations, Water Resour. Bull., 31, 657-669, 1995.

Rees, W. G.: Remote Sensing of Snow and Ice, CRC Press, Boca Raton (FL), 2005.

Rhyner, J., Bründl, M., Etter, H. J., Steiniger, M., Stöckli, U., Stucki, T., Zimmerli, M., and Amman, W.: Avalanche warning Switzerland - consequences of the avalanche winter 1999, in: Proceedings of the 13th Int. Snow Science Workshop, 30 September-3 October, Penticton, B.C., Canada, 2002.

Robinson, D. A. and Frei, A.: Seasonal Variability of Northern Hemisphere Snow Extent Using Visible Satellite Data, The Professional Geographer, 582, 307-314, 2000.

Romanov, P., Gutman, G., and Csiszar, I.: Satellite-derived snow cover maps for north America: Accuracy Assesement, Adv. Space Res., 30, 2455-2460, 2002.

Scherrer, S. C. and Appenzeller, C.: Swiss Alpine snow pack variability: major patterns and links to local climate and large-scale flow, Clim. Res., 32, 187-199, doi:10.3354/cr032187, 2006.

Scherrer, S. C., Appenzeller, C., and Laternser, M.: Trends in Swiss Alpine snow days: The role of local- and largescale climate variability, Geophys. Res. Lett., 31, L13215, doi:10.1029/2004GL020255, 2004.

Scherrer, S. C., Wüthrich, C., Croci-Maspoli, M., Weingartner, R., and Appenzeller, C.: Analyses of newly digitized and reconstructed snow series over the last $100+$ years in Switzerland, EMS Annual Meeting Abstracts Vol. 7, EMS2010-514, 13 17 September, Zürich, 2010.

Scherrer, S. C., Wüthrich, C., Croci-Maspoli, M., Weingartner, R., and Appenzeller, C.: Snow variability in the Swiss Alps 18642009, Int. J. Climatol., 33, 3162-3173, doi:10.1002/joc.3653, 2013.
Stucki, T., Duerr, L., and Etter, H.: Schnee und Lawinen in den Schweizer Alpen. Winter 2005/06. Wetter, Schneedecke und Lawinengefahr. Winterbericht SLF, Tech. rep., Davos, WSLInstitut für Schnee- und Lawinenforschung SLF, 2011.

Tiao, G. C., Reinsel, G. C., Xu, D., Pedrick, J. H., Zhu, X., Miller, A. J., DeLuisi, J. J., Mateer, C. L., and Wuebbles, D. J.: Effects of autocorrelation and temporal sampling schemes on estimates of trend and spatial correlation, J. Geophys. Res., 95, 20507-20517, 1990.

Valt, M. and Cianfarra, P.: Recent snow cover variability in the Italian Alps, Cold Reg. Sci. Technol., 64, 146-157, doi:10.1016/j.coldregions.2010.08.008, 2010.

Voigt, S.: Advanced methods for operational mapping of Alpine snow cover using medium resolution optical satellite data, Inauguraldissertation, University of Bern, Switzerland, 2000.

Wang, X. and Xie, H.: New methods for studying the spatiotemporal variation of snow cover based on combination products of MODIS Terra and Aqua, J. Hydrol., 371, 192-200, doi:10.1016/j.jhydrol.2009.03.028, 2009.

Wang, X., Xie, H., and Liang, T.: Evaluation of MODIS snow cover and cloud mask and its application in Northern Xinjiang, China, Remote Sens. Environ., 112, 1497-1513, 2008.

Wang, X., Xie, H., Liang, T., and Huang, X.: Comparison and validation of MODIS standard and new combination of Terra and Aqua snow cover products in northern Xinjiang, China, Hydrol. Process., 429, 419-429, doi:10.1002/hyp.7151, 2009.

Weatherhead, E. C., Reinsel, G. C., Tiao, G. C., Meng, X.-L., Choi, D., Cheang, W.-K., Keller, T., DeLuisi, J., Wuebbles, D. J., Kerr, J. B., Miller, A. J., Oltmans, S. J., and Frederick, J. E.: Factors affecting the detection of trends: Statistical considerations and applications to environmental data, J. Geophys. Res., 103, 1714917161, doi:10.1029/98JD00995, 1998.

Wiscombe, W. J. and Warren, S. G.: Model for the Spectral Albedo of Snow. I : Pure Snow, Engineering, 37, 2712-2733, 1980.

WMO: Implementation Plan for the Global Observing System for Climate in Support of the UNFCCC (2010 Update), Tech. Rep. 1523, Global Climate Observing System, http://eprints.soton.ac. uk/162953/ (last access: 18 June 2012), 2010.

WMO: Systematic Observation Requirement for Satellite-based Data Products for Climate (Update 2011), GCOS-154, Tech. rep., World Meteorological Organization, Geneva, 2011.

Zhao, H. and Fernandes, R.: Daily snow cover estimation from Advanced Very High Resolution Radiometer Polar Pathfinder data over Northern Hemisphere land surfaces during 1982-2004, J. Geophys. Res., 114, D05113, doi:10.1029/2008JD011272, 2009. 